Chapter 21

\title{
FUTURE OF AGRICULTURAL RESEARCH
}

\section{David Zilberman}

Increased application of scientific knowledge has been a major contributor to feeding a growing population at higher per capita food levels while decreasing use of land and labor per unit of food (Goldewijk 2001). ${ }^{1}$ However, growth in agricultural productivity varied significantly by location and crop, as was emphasized by Ritchie and Roser (2017) and in Chapters 3 through 7 of this book. This heterogeneity is associated to a large extent with varying application of scientific knowledge and advanced technology (Evenson and Gollin 2003). The coming decades will further challenge our agricultural system to meet the needs of a growing population and shifting demands of consumers, as well as to address the implications of climate change.

This chapter addresses some of the basic questions regarding agricultural research systems, especially in the context of developing countries, raised in the preceding chapters. Increased urbanization and urban food demand, as well as increasing per capita income, will lead to greater demand for high-value products, including fruits, vegetables, and animal-sourced foods (Chapters 9 and 10). Modern food value chains have emerged in response to such structural changes in food demand (Chapters 11 and 12). However, undernutrition, food insecurity, and poverty are persistent issues in many developing countries (Chapter 10). Building new equitable and viable agrifood systems will be one of the major issues of agricultural development in the coming decades. This chapter asks what agricultural research should be done, who should do it, and who should pay for it. A major challenging global issue in agricultural development is how to cope with climate change (Chapter 19), which accompanies deteriorating stock of natural resources (Chapter 18) and growing water scarcity (Chapter 20). Here too, the questions arise as to who should do what kind of agricultural research and who should shoulder the cost.

1 I would like to thank Joel Ferguson, Ben Gordon, and Jed Silver for excellent assistance. 
To answer these questions, this chapter analyzes the innovation supply chains, relying on multiple bodies of literature. Some of the major and specific challenges identified in the previous chapters, which ought to be addressed by agricultural research, are discussed. Finally, the chapter explores the policy implications of this analysis. One major conclusion is that agricultural research can adequately enhance capacity to feed humans as well as address social welfare and climate change considerations by actively investing in research excellence around the world. This includes developing effective mechanisms of technology transfer from the lab to the field and the factory and from developed to developing countries, as well as relying on sound regulatory frameworks that allow scientific results to flourish while maintaining adequate levels of safety. It is also of paramount importance that sufficient public and private sources of funding are allocated to agricultural research and development $(\mathrm{R} \& \mathrm{D})$ efforts, managed in ways that allow these efforts to be most effective.

\section{Innovation Supply Chains}

Agricultural research is part of an evolving system of general scientific knowledge, product development and food supply chains, and political economy forces that affect allocation of resources and funding to agricultural research. Furthermore, agriculture itself is going through a major transformation, and research is both a contributor to and an outcome of this transformation. Previous chapters have discussed induced innovation as well as political economy of agricultural policy, including in relation to agricultural research (Chapters 1,2, and 14). This section focuses on an emerging topic related to the innovation process - that is, innovation supply chains.

To understand how innovations are carried out, it is important to understand the innovation supply chains connecting major players in agricultural research. Most innovations start with a new idea and subsequently there are several steps to bring the idea to an implementable product or practice. These steps can be defined as the research and development process, which may be different for different types of innovation. While many important innovations originated with practitioners, the share of innovations initiated with scientific discovery is increasing. Once a discovery is made, it needs to be verified and quantified both in terms of efficacy and safety, and then it needs to be scaled up and, if it is embodied in products, an industrial and commercialization process needs to be established. The next stage is dissemination of 
information so that it can reach the final users. For simplicity, I treat research that leads to discoveries as basic research. ${ }^{2}$

I refer to upscaling and testing as applied research, and commercialization can be viewed as development of the innovation. Dissemination can be carried out by private firms through marketing efforts as well as by public extension, and at times both. The R\&D and dissemination activities may be done by different organizations, and the innovation supply chain consists of activities that lead from discovery to implementation in terms of product or practice. Table 21.1 illustrates the different stages and types of the innovation supply chain.

There may be different configurations of the innovation supply chain. One configuration that has become prominent in developed countries, especially the United States, is the educational-industrial complex, where innovations originate at research institutions, like universities. Table 21.1 illustrates two typical patterns under the educational-industrial complex, in one case where a technology transfers from a university to a company and another in which it goes from university through a start-up to a company. These innovations are typically patented, and the rights to develop them are sold to private companies or start-ups. These start-ups may become major corporations themselves or be acquired by large corporations. Graff, Heiman, and Zilberman (2002) documented this process of technology transfer, which served as a crucial element of the emerging medical and agricultural biotechnology sectors. Similar processes of interaction between universities and the private sector were important for innovations like the tomato harvester (Rasmussen 1968). One of the most important elements of the educational-industrial complex is the involvement of university researchers with the commercialization of their ideas.

The intrinsic knowledge held by innovators is often essential for commercialization, and the intense interaction between universities and the private sector has contributed to the overall performance of technological advances. These developments are consistent with the recent findings of Etzkowitz et al. (2000) that universities have played an increasingly important role in supporting private industry and government in an increasingly knowledge-based economy. The literature emphasizes that the innovation supply chain is not linear, and new innovations may emerge from experience in the field as well

2 Agricultural sciences are a form of applied research and use findings in other fields. From my perspective this discovery research is basic research. 
TABLE 21.1 The innovation process

\begin{tabular}{|c|c|c|c|c|}
\hline \multirow{2}{*}{$\begin{array}{l}\text { Stages of the } \\
\text { innovation process }\end{array}$} & \multicolumn{2}{|c|}{ Educational-industrial complex } & \multicolumn{2}{|c|}{ International innovation systems } \\
\hline & Arrangement 1 & Arrangement 2 & Arrangement 1 & Arrangement 2 \\
\hline Research & \multirow{2}{*}{ University } & \multirow{2}{*}{ University } & \multirow{2}{*}{ CGIAR $^{*}$ centers } & \multirow{2}{*}{ CGIAR centers } \\
\hline Discovery & & & & \\
\hline Development & \multirow{2}{*}{ Start-up } & \multirow{4}{*}{$\begin{array}{c}\text { Major } \\
\text { corporations }\end{array}$} & $\begin{array}{l}\text { National } \\
\text { Aariculture }\end{array}$ & National \\
\hline $\begin{array}{l}\text { Patent (if applicable) } \\
\text { and approval }\end{array}$ & & & $\begin{array}{l}\text { Research } \\
\text { System }\end{array}$ & Agriculture \\
\hline Production & \multirow{2}{*}{$\begin{array}{c}\text { Major } \\
\text { corporations }\end{array}$} & & Private firms & \\
\hline Dissemination & & & $\begin{array}{l}\text { Private firms/ } \\
\text { extension }\end{array}$ & Extension \\
\hline Adoption & Farmers & Farmers & Farmers & Farmers \\
\hline
\end{tabular}

Source: Based on Graff, Heiman, and Zilberman (2002).

Note: *Formally known as the Consultative Group on International Agricultural Research.

as commercialization of products. Interaction between researchers at different institutions is becoming more fluid. Structures akin to the educationalindustrial complex are emerging in developing countries, where private firms are assuming a greater role in the application and introduction of technologies. Pray (2001) provides examples from Brazil, China, and India, where new forms of private-public partnerships are emerging to carry out basic research in plant breeding. Fuglie et al. (2012) emphasize the growing importance of private-sector research in the development and introduction of chemicals and mechanical solutions to agricultural problems in developing countries. This research has benefited from important transfers of knowledge through foreign direct investment as well as other forms of interaction with advanced research institutions.

Another structure quite prevalent in developing countries is an international/national innovation system where CGIAR, working with researchers at universities in developing and developed countries, conducts some of the fundamental research, such as developing a new variety or pest control strategy for a specific location, and then this technology may be transferred to the National Agriculture Research System (NARS) for further adaptive research (see Table 21.1). Sometimes the NARS may release their technologies through extension directly to farmers, and at other times they transfer it to private firms with their own marketing efforts and extension.

The public-sector research and outreach system based on the CGIAR and NARS can provide a base to supply food in developing countries. But the 
agrifood sectors of the developing world would benefit from the emergence of private-sector research, development, and marketing. Indeed, Pray and Fuglie (2015) show that private agricultural R\&D has been growing faster than public $R \& D$ in recent decades, and there is a complementarity between public and private research. Graff and Zilberman (2001) suggest that public intellectual property should be managed to optimize net social benefit, and they suggest establishing a clearinghouse that would obtain access to intellectual property for applications that are not likely to be pursued by the private sector but could significantly benefit society, especially the poor in developing countries and specialty crops generating low volumes of income. However, Spielman and $\mathrm{Ma}$ (2016) find that intellectual property protection, either biologically through the use of hybrids or legally through enforcement of patents and other means, allows domestic seed industries to evolve in developing countries and contribute to the reduction of the gap in productivities between developing and developed countries.

The nature of the innovation supply chain varies by the nature of the technology. When it comes to technologies that are embodied in products, the private sector plays a much greater role. The large literature on technology diffusion (Feder, Just, and Zilberman 1985) emphasizes the importance of economic factors, like pricing, risk considerations, lack of credit, and regulations in introducing technologies. It argues that the diffusion of technologies is gradual due to heterogeneity among potential adopters and that processes of learning-by-doing and learning-by-using increase the attractiveness of new technologies and expand the range of adopters. Adoption may be hindered by uncertainty, and hence marketing efforts, like demonstrations, sampling, and money-back guarantees, are important for inducing adoption (Zilberman, Zhao, and Heiman 2012). Furthermore, implementation of innovations may require the establishment of particular supply chains - that is, the food value chain discussed in Chapter 12.

The design of the supply chain determines the capacity to disseminate the new technology, its price, and marketing strategy. One of the key roles of supply chains is provision of credit as well as insurance, as lack of credit and risk are major obstacles for adoption of new technology (Zilberman, Lu, and Reardon 2017). For example, growing flowers in Kenya can be viewed as an innovation, which may require research with respect to varieties and practices, but the main challenge is the establishment of a value chain, which includes nurseries for genetic material, farms to grow flowers, and then systems of processing and shipping. In the case of embodied technologies with increasing economies of scale in production, such as tractors and sprayers, many early 
adopters will lease the technology from a technology provider, and over time users will own the technology (Du et al. 2016).

The public sector may play a bigger role in the innovation supply chain for disembodied technologies, such as improved cultural practices, which are basically characterized by public goods. Public-sector extension agents are especially important in disseminating technologies that are relatively easy to implement and that do not require much human capital. However, when implementation of agricultural practices requires significant human capital, it may lead to the emergence of specialized consultants and information services (Wolf 1995). There is a growing sector of specialized consultants for irrigation, waste management, and pest control, and farmers' choices and views are affected by these sources of information (Lichtenberg and Zimmerman 1999).

\section{Reshaping Agricultural Research to Tackle Future Challenges}

The evolution of agriculture provides the background to assess some of the challenges faced by agricultural research and how they can be addressed. These challenges are multidimensional. On the one hand, agriculture needs to produce more food, estimated at 60 percent to 70 percent more by 2050 than in 2005 (FAO 2009). On the other hand, agriculture needs to address challenges of climate change as well as heterogeneity among regions and even among farmers in the same community in terms of productivity and capacity and the need to develop value-added agriculture. These issues have been identified as key challenges highlighted in previous thematic chapters. I address each of these issues with the consideration that agricultural research must be smallholder-friendly for poverty reduction and equitable development. In addition, I touch upon inherent issues about agricultural research, such as use of microlevel data and funding for agricultural research.

\section{Increase Productivity}

Although agricultural productivity gains have been remarkable during the past 150 years, the rate of increase has been declining more recently (Alston, Beddow, and Pardey 2009). Alston, Beddow, and Pardey (2009) argue that much of this decline is due to reduced public investment in agricultural research and the major emphasis of research on issues unrelated to productivity. Given increasing population, decreasing room for expansion of agricultural land, and climate change, continued emphasis on the enhancement of productivity is obviously warranted. According to Chapter 19, as long as investment 
in agricultural research increases and emphasizes input use efficiency and effective use of water and other resources, overall agricultural production is likely to meet the growing demand at modestly higher food prices. This analysis, however, does not explicitly consider some of the emerging breakthroughs in the life sciences, including agricultural biotechnology developments such as gene editing. These technologies can improve yields, reduce pesticide use, and enhance product quality. There is evidence that the use of Bt corn can even reduce postharvest risk, which has become a major concern (Wu 2006).

Investment in research to enhance productivity would allow countries to expand food production and prevent deforestation for expansion of agricultural land and deterioration of soil fertility. Improved crop and water management and technology, such as enhanced water harvesting, conservation tillage, and small-scale precision farming that optimizes application of water and other inputs within the field, are important means to improve yields in both irrigated and rainfed settings as are continued investments in high-efficiency irrigation in irrigated settings (Chapter 20). And here, the ability to take advantage of these advanced technologies depends, to a large extent, on the political will.

The recent experience with genetically modified crops suggests how regulations can hinder a technology reaching its potential. While Klümper and Qaim (2014) and Barrows, Sexton, and Zilberman (2014) show that adoption of genetically modified crops has enhanced yields, increased farmers' income, and decreased use of pesticides in the few countries and for the few crops where it has been adopted, it is far from reaching its potential. Regulations, in particular, hamper the ability of developing countries, especially in Asia and Africa (Herring and Paarlberg 2016). The case of golden rice (Wesseler and Zilberman 2014) demonstrates the immense monetary and human health loss due to regulatory delay; and the bans on technologies developed in and for Africa show the large cost of regulation in terms of malnutrition (Wesseler et al. 2017). Furthermore, costly and uncertain regulations of new technologies tend to reduce investment in these technologies in university research, and most important, in the private sector, which commercializes new knowledge throughout the innovation supply chain. From the viewpoint of political economy (discussed in Chapter 14), equilibrium with undesirable regulations should be broken by providing scientifically correct information about genetically modified crops.

Genetic modification was one of the first major applications of modern molecular and cellular biology in agriculture. With more recent breakthroughs, such as gene editing, the potential for new innovation is immense. 
The extent of the societal gain from these technologies depends on the development of a regulatory framework that (1) balances the benefits of these technologies with sound risk considerations and (2) uses adaptive management where some experimentation is allowed with new technologies before largescale use (Bradford et al. 2005). Furthermore, the capacity to take advantage of these promising new tools depends on an expanded network of research centers that study how and when new technology packages can be applied effectively throughout the world. Foley et al. (2011) suggest that the major discrepancy in terms of productivity between regions points to a large potential to increase yield and efficiency as technologies are introduced.

However, introduction of new varieties and production methods is not feasible without applied research that allows for adaptation and an effective supply chain for dissemination of these technologies. This further emphasizes the important role of a wide network of research stations associated with privatesector firms and extension distributed throughout the world. The ability to introduce more productive systems will benefit from the transformation of agricultural systems, introduction of advanced supply chains, and improved transportation and information technologies as well as demographic changes in agriculture.

\section{Address Heterogeneity}

The differences between regions in terms of productivity are among the most notable features of agrifood systems around the world (Chapters 3-8). No less important is the heterogeneity of productivity among farmers even in the same areas (Chapter 11). Needless to say, agricultural productivity and welfare or poverty are intimately related, so that in order to eradicate poverty, enhancing agricultural productivity in left-out areas is indispensable. Different regions have different research and agrifood systems. Advanced countries, to some extent, have strong research universities, effective agribusiness firms, robust infrastructure, and safety nets. Middle-income countries have many of the same features, while low-income countries lack these features, in part or whole.

Low-income countries, though, are generally most vulnerable to climate change, and their production practices and yields lag substantially. While these countries will continue to be dependent on CGIAR centers in the foreseeable future, policies that are focused on developing stronger national research centers and extension to adapt and develop technologies are crucial (Chapter 11). The work of Evenson and Kislev (1975) emphasizes the importance of excellence in research in being able to identify the best suited cultivars. Thus each 
region should pursue establishing centers of agricultural research excellence. Sanchez (2010) emphasizes the complementarity between agricultural practices and inputs, and thus research centers should have expertise in multiple aspects of agricultural production (for example, soil, water, fertilizers, seeds, and so on). In addition to establishing strong NARS, the decentralized extension system, which can deal with technology diffusion in vastly heterogeneous production environments, must be developed (Chapter 11). Furthermore, the public sector should not operate in isolation but rather develop links and alliances with the private sector that must grow even in the least developed countries in order to take advantage of new knowledge and opportunities to establish mechanisms for dissemination of new technologies.

The issue of heterogeneity is particularly relevant for natural resource management or NRM (Chapter 18). One clear finding from the existing studies is that the performance of NRM technologies, individually or in combination, varies considerably across different contexts (for example, by soil type), and their adoption also varies considerably as a consequence of this heterogeneity as well as socioeconomic variation (for instance, land rights, wage rates, and degree of market development). Therefore, research can probably have the largest impact by better understanding which of the existing NRM practices are likely to be most suitable for different contexts. Another clear finding is that desirable NRM practices or rules are insufficiently applied if measured by physical indicators of sustainability such as land degradation or water availability. So agricultural R\&D could usefully reallocate funds away from pure technological research into understanding of institutional and socioeconomic factors, how practices can be adapted to fit better into local contexts in the short run, and how to improve the institutional environment in the longer term.

\section{Develop Value-Added Agriculture}

Rural poverty and low income have been major problems in both developed and developing countries, stemming from inelastic demand for agricultural commodities and technological change. Agricultural policies should aim to ameliorate these problems by transforming the rural economy (Chapters 11 and 12), but migration away from agriculture and larger farm operations have contributed to addressing them (Schultz 1964; Gardner 1992). In fact, the economic potential and viability of small subsistence farms in developing countries is limited (Hazell 2005). An increase in farm size is a key step for increasing farm incomes, and the development of labor-saving technology, such as mechanization, is a prerequisite for farm size expansion. Foster and Rosenzweig (2017) provide evidence from India showing that labor market 
frictions explain the persistence of small farms, but that this inhibits optimal machine use that takes advantage of economies of scale. Preservation of small farms is inefficient and exacerbates poverty. The seminal paper by Kislev and Peterson (1982) suggests that farmers in developed countries were pulled by higher urban incomes, which led to increases in farm size that helped remaining farmers to increase their income.

Urbanization and the development of local towns will be facilitated by the development of such technology (Chapters 9 and 11). Another avenue is to increase value-added of agricultural products both on the farm and in rural areas (Thirtle, Lin, and Piesse 2003). Value-added agriculture can be achieved by increasing production of specialty crops (for example, fruits, vegetables, flowers) and transition from basic commodities to differentiated products (for instance, corn or potato with unique nutritional or taste characteristics). The bifurcated nature of agriculture, where a small share of higher-income consumers has significant willingness to pay for uniquely produced agricultural products (for example, organic, exotic crops), can benefit the rural sector. As income grows, emphasis on differentiated, high-quality products should become a major priority for the agricultural sector (Chapter 11). However, development of value-added agriculture requires additional knowledge, sophisticated supply chains, and supportive policies. Also needed are innovative credit and insurance programs to facilitate the adoption of potentially profitable but possibly risky production of high-value products (Chapters 16 and 17).

Chapter 10 has clearly shown that many nutritious foods are very expensive in poor countries, which is likely to result in undernutrition. Thus the reduction of prices of nutrient-dense foods is an urgent issue, and diversifying agricultural R\&D into nonstaple foods is the way to go. Also indispensable are related investments in extension and veterinary services, as many highvalue products are new to farmers and the population of livestock is expected to increase. Also important for the development of value-added activities is the development of food-processing technologies and transport systems of fresh farm products. For example, agricultural research on solar-powered postharvest drying and refrigeration technologies could have a high payoff.

Value-added agriculture can benefit from the expansion of the bioeconomy. This is the growing part of the economy that uses advances in life sciences and utilizes living organisms to produce goods and services. Besides food products, the bioeconomy produces fuels, chemicals, and medical products (Wesseler and von Braun 2017). It is a key to transitioning from relying on nonrenewable resources to a sustainable economy. Agricultural research should be expanded to include production of multiple products from agricultural 
feedstocks, as expansion of the range of products produced by agriculture will increase the well-being of the rural sector (Zilberman et al. 2013). While there has been significant debate about diversion of agricultural resources away from food to produce biofuels, and it seems that in the short run there have been some negative effects of biofuels on poverty, with the right policies, biofuels and poverty reduction are not substitutes but can complement one another (Kline et al. 2017). In other words, agricultural research to boost productivity and promote utilization of agricultural resources can contribute to both supply of ample food and enhancement of farmers' income.

\section{Adapt to Climate Change}

Although the scientific understanding of climate change and ability to predict its impacts are improving, they are still shrouded in uncertainty. Nevertheless, climate change will have a significant impacts on agrifood systems that will require, and already have prompted, major adaptations. Climate change is likely to result in (1) migration from regions closer to the tropics to regions closer to the poles, (2) rising sea levels and loss of coastal lands, (3) increased snow and ice melt as well as changes in supply of surface water, and (4) increased probability of extreme events with increased likelihood of fires, floods, and droughts.

The responses to climate change ought to include innovation and adoption of new technologies, changes in land use and trade patterns, development of insurance schemes, and investment in risk-reducing capacity (Zilberman, Zhao, and Heiman 2012). Climate change may require significant relocation. It will provide new opportunities for agricultural settlements in northern regions (for example, Canada, Russia) and may result in losses in opportunities closer to the equator. Thus climate change may result in climate migrants and refugees; and the ability to deal with this challenge is a major policy issue (Olmstead and Rhode 2011). Since social adaptation to migration is difficult and costly, research that allows for adaptation of agricultural and food systems to changes in climate will have significant value. Adaptation will benefit from the use of modern biotechnology tools to accelerate development of new varieties and the capacity to develop agronomical practices to use them effectively. Examples are development of flood-, drought-, disease- and pestresistant, heat-tolerant, and water-saving varieties. For example, plant breeding can improve plant biomass per unit of water through transpiration rates and efficiency of biomass growth per unit of transpiration.

In the face of increasing climate risk, efficient insurance contracts will become critically important (Chapter 17). The development of improved 
varieties with a variety of resistant traits will contribute to the stabilization of crop yield, which will reduce the risk of production. This will increase the demand for credit and helps justify calls for institutional finance (Chapter 16). If crop insurance markets fail, stabilization of crop yield will aid in consumption smoothing.

Nitrous oxide and methane are major greenhouse gases emitted from agriculture. Thus, also needed is agricultural research on the development of nitrogen-efficient varieties that would allow lower use of fertilizer and reduced nitrous oxide emissions from agriculture, and farming practices to reduce methane emission from paddy fields. Breeding cattle for lower methane emissions will also contribute to the mitigation. Spatial changes in climate and water resource distribution will require significant investment in infrastructure, including dams, waterways, processing facilities, and so on. Since timing of responses to climate change is essential, it is important not only to develop better technical decision tools but also to improve political decision-making processes that do not impose unnecessary constraints. Finally, also important will be research that improves predictions of extreme climate events, designs mechanisms to cope with them, and develops guidance for policies, infrastructure design, and farming systems that are more resilient to possible changes.

Reardon and Zilberman (2018) also suggest that climate change may affect the rural sector through its impact on food value chains. Disruption of supply chains as a result of climate events may harm farmers dependent on them. Agribusiness firms may elect to invest in farming activities in regions more resilient to climate change. Thus awareness of these links and research and decision-making that takes them into account will improve adaptive capacity to climate change. Because of the uncertainty regarding climate change and its impacts, climate policies and research need to be designed within a larger context of agrifood growth and development. Combatting climate change does not mean reducing the effort to address food security. Policy design should emphasize "no regrets" policies that address climate challenges while addressing other crucial agricultural issues in an efficient and equitable manner (Lipper et al. 2018).

\section{Use Microlevel Data}

The recent expansion of microlevel data has led to better understanding and measurement of the internal workings of biological, physical, and social systems. In the case of physics and chemistry, the understanding of the atom and the development of electricity allowed transition from mechanical systems to electronic systems and now systems that manipulate nanodata. The discovery 
of DNA enabled plant biologists to move from selective breeding to biotechnology. In social and managerial sciences, we see the increased use of big microlevel behavioral data matched with biophysical and climatic data. This refined knowledge allows for greater disaggregation, enabling deeper analysis of microbehavior that addresses heterogeneity. The challenge in all fields is to develop a method that takes advantage of these new data and opportunities. Both precision agriculture and genetic engineering are based on the availability of new data. The availability of these new data will be key to more precise and effective supply chains. Einav and Levin (2014) suggest that the big data revolution will allow more refined understanding of the impact of policies and technologies, and help develop policies that adjust to heterogeneity and randomness. Mullainathan and Spiess (2017) suggest that machine learning would complement and enable more effective estimation and identify links that have not been used by traditional methods.

However, the challenge is to be able to make sense of the new available data and to reconcile microsystems and macrosystems. In biology there is a challenge to understand the functions of microelements in a bigger system and to realize the relationships between ecosystems and different organisms within them. In economics and management there is a challenge to integrate microrelationships and macrorelationships, and to use them in harmony. Furthermore, linked models at different degrees of aggregation are required to understand and develop policy related to climate change. We have seen this emerge through the integrated use of programming, econometrics, and general equilibrium for the case of biofuels (see Khanna and Zilberman 2012). But this is a modest beginning and the new data, as well as fresh approaches in econometrics and artificial intelligence, provide novel opportunities for policy and management analysis.

While data science is providing new opportunities, the challenges we face are immense. How do we incorporate narratives in empirical analysis for policy assessment? How do we take advantage of human ingenuity in interpreting emerging data sources? How do we increase efficiency to users and practitioners in using looming data-intensive technologies? Finally, how do we prevent abuse of expanding data sources?

\section{Expand Resource Availability for and Effectiveness of Agricultural Research}

The literature on the political economy of research (Rausser, Swinnen, and Zusman 2011) suggests that the funding and direction of public research represent political choices and aim to meet the objectives of governments, donors, 
multilateral organizations, NGOs, and environmental groups as well as the private sector. The development of the research agenda in the Global North to some extent affects the research that is done in the Global South. For example, donor countries' growing concerns about climate change and its implications in terms of migration and food security are likely to reemphasize adaption to climate change and prevention in the agricultural research agenda.

Similarly, issues of gender and sustainability are likely to be promoted by donors. The European objections to GMOs (genetically modified organisms) may reduce the weight in research done on GMOs in developing countries. Private actors may support activities that will enhance the reliability and quality of their supply and enhance the demand for their products. Research administrators have to delicately balance the different objectives of their major supporters and obtain funds without strings attached in order to pursue the most appropriate research agenda. (Defining this concept is its own topic of research.) One of the major challenges of research management is to obtain and allocate resources to basic research. The seminal paper by Rosenberg (1990) suggests that the value of this research and its spillovers may, from a social perspective, exceed the returns of targeted research efforts.

\section{Conclusion and Summary}

Agricultural research is challenged to address multiple societal issues, including sufficient and healthy foods, improved protection of the environment, and growing income for the agrifood sector. Its future, to a large extent, will depend on major policy decisions, both in the private and public sectors. A clear understanding of the major features of the agricultural sector, and agricultural technology in particular, is critical in designing policies to allow agricultural research to be a source of value and benefit for society.

Agricultural research is an essential element of the innovation supply chain, and its impact is hampered by not taking advantage of and establishing systems that may complement research within agricultural supply chains. In particular, establishing effective links between public and private research is important. The analysis suggests that public research and private research, in many cases, are not substitutes but rather complements. Basic knowledge produced by the public sector provides a foundation to much of the commercialization efforts of the private sector. While the educational-industrial complex will play a growing and important role in developed countries, expanding this model elsewhere can enhance research productivity. In this model, public research results are transferred to the private sector and then expanded and 
commercialized, and researchers are actually involved in expansion and commercialization processes.

For this research model to be effective, it is important to develop strong support for basic research at universities, develop a legal framework for technology transfer, and develop a culture that encourages collaboration between academics and practitioners. To be socially effective, the educationalindustrial complex requires efficient management and utilization of intellectual property. This includes high thresholds for patenting as well as nonexclusive transfer of rights for process innovations and mechanisms to ensure access to patents needed for products to address the needs of the poor and developing countries. Support for research is provided not only in terms of direct support but also tax and other incentives to researchers and others to pursue work on public goods research.

While development of private-sector research capacity in developing countries is desirable and important, the public sector will continue to play a major role in development of agricultural innovations for the poor in developing countries. Sufficient investment in these capabilities is important and probably will continue to rely on internal funds as well as foreign aid. Strengthening the NARS and extension system is important as well, and these public-sector activities should be encouraged to improve, but not constrain, the evolution of stronger private-sector research, especially technology delivery. Appropriate division of efforts between the public and private sectors is needed to effectively introduce and disseminate new technologies. Furthermore, given the human capital and other constraints on the capacities of the private sector in developing countries, foreign direct investment in agricultural research, within limits, may contribute significantly to enhancing productivity.

CGIAR will continue to have a major role in providing the foundation for the development of agricultural technologies in developing countries. Development of research and education excellence in developing countries can contribute to the human capital and knowledge base needed to develop new technologies and apply them to specific conditions. That may suggest investment in establishing centers of excellence in research, development, and extension throughout developing countries. Some of them may be an outgrowth of the existing CGIAR centers. In addition, the example of the educationalindustrial complex suggests that involvement of CGIAR centers and researchers in developing countries in further development and commercialization of technologies can accelerate the agricultural development process.

Another important dimension of policy is regulation. While regulations are essential to prevent mishaps, reduce risk, and control externalities, 
excessive regulation can be a significant hindrance to new technologies, both directly by preventing their use and indirectly by discouraging investment in new research. As argued earlier, the developing world has not gained much of the potential benefits from the introduction of new agricultural biotechnology tools because of excessive regulation. Furthermore, scarce resources have been diverted away from agricultural research to regulatory compliance. Introduction of more sound regulations is also important in developed countries, especially Europe, because we are at risk of losing some of the potential gains from modern biotechnology in agriculture. Agricultural research must recognize the evolution of agricultural and agrifood systems, and a growing priority should be given to investigate improved productivity of agrifood systems beyond the farm-gate. While studying crop and livestock systems will continue to be important elements of research, increased focus on storage, transportation, processing, and even utilization of food will be of much importance. Future research on these aspects should be on technological parameters but also emphasize the social and political implications of agrifood systems and how to design such systems to enhance social welfare and equity.

Agrifood systems will continue transforming. The economic viability of subsistence farmers is limited, and agricultural research can help some smallholders transition to a more viable scale of operation, add new value-added activities, and usher in agriculture to be a main contributor to and beneficiary of a growing bioeconomy. Agricultural research is likely to play a major role in guiding agriculture through adaptation to climate change, changes in land use, adoption of new technologies, and relocation, as well as provision of new sources of income from mitigation efforts. Finally, the ongoing information and biotechnology revolutions are likely to transform agriculture in significant ways. The challenge as researchers is to help make these transformations beneficial to the poor, consumers, society as a whole, and the environment.

\section{References}

Alston, J. M., J. M. Beddow, and P. G. Pardey. 2009. “Agricultural Research, Productivity, and Food Prices in the Long Run.” Science 325 (5945): 1209-1210.

Barrows, G., S. Sexton, and D. Zilberman. 2014. "Agricultural Biotechnology: The Promise and Prospects of Genetically Modified Crops." Journal of Economic Perspectives 28 (1): 99-119.

Bradford, K. J., A. Van Deynze, N. Gutterson, W. Parrott, and S. H. Strauss. 2005. "Regulating Transgenic Crops Sensibly: Lessons from Plant Breeding, Biotechnology and Genomics." Nature Biotechnology 23 (4): 439-444. 
Du, X., L. Lu, T. Reardon, and D. Zilberman. 2016. "Economics of Agricultural Supply Chain Design: A Portfolio Selection Approach." American Journal of Agricultural Economics 98 (5): 1377-1388.

Einav, L., and J. Levin. 2014. "The Data Revolution and Economic Analysis." Innovation Policy and the Economy 14 (1): 1-24.

Etzkowitz, H., A. Webster, C. Gebhardt, and B. R. C. Terra. 2000. "The Future of the University and the University of the Future: Evolution of Ivory Tower to Entrepreneurial Paradigm." Research Policy 29 (2): 313-330.

Evenson, R. E., and D. Gollin, eds. 2003. Crop Variety Improvement and Its Eon Productivity: The Impact of International Agricultural Research. Wallingford, UK: CABI Publishing.

Evenson, R. E., and Y. Kislev. 1975. Agricultural Research and Productivity. New Haven, CT: Yale University Press.

FAO (Food and Agriculture Organization of the United Nations). 2009. "How to Feed the World in 2050." In Rome: High-Level Expert Forum. Rome.

Feder, G., R. E. Just, and D. Zilberman. 1985. "Adoption of Agricultural Innovations in Developing Countries: A Survey." Economic Development and Cultural Change 33 (2): 255-298.

Foley, J. A., N. Ramankutty, K. A. Brauman et al. 2011. "Solutions for a Cultivated Planet." Nature 478 (7369): 337-342.

Foster, A. D., and M. R. Rosenzweig. 2017. "Are There Too Many Farms in the World? LaborMarket Transaction Costs, Machine Capacities and Optimal Farm Size.” NBER Working Paper 23909. Cambridge, MA: National Bureau of Economic Research.

Fuglie, K., P. Heisey, J. King, C. E. Pray, and D. Schimmelpfennig. 2012. "The Contribution of Private Industry to Agricultural Innovation." Science 338 (6110): 1031-1032.

Gardner, B. L. 1992. "Price Supports and Optimal Spending on Agricultural Research.” Working Paper 92-20. Department of Agricultural Economics, University of Maryland, College Park.

Goldewijk, K. K. 2001. "Estimating Global Land Use Change over the Past 300 Years: The HYDE Database." Global Biogeochemical Cycles 15 (2): 417-433.

Graff, G., A. Heiman, and D. Zilberman. 2002. “University Research and Offices of Technology Transfer." California Management Review 45 (1): 88-115.

Graff, G., and D. Zilberman. 2001. "An Intellectual Property Clearinghouse for Agricultural Biotechnology." Nature Biotechnology 19 (12): 1179-1180.

Hayami, Y., and V. W. Ruttan. 1971. Agricultural Development: An International Perspective. Baltimore: Johns Hopkins University Press.

Hazell, P. B. 2005. “Is There a Future for Small Farms?” Agricultural Economics 32 (s1): 93-101. 
Herring, R., and R. Paarlberg. 2016. "The Political Economy of Biotechnology." Annual Review of Resource Economics 8: 397-416.

Janssen, E., and J. Swinnen. 2019. “Technology Adoption and Value Chains in Developing Countries: Evidence from Dairy in India." Food Policy 83: 327-336.

Khanna, M., and D. Zilberman. 2012. "Modeling the Land-Use and Greenhouse-Gas Implications of Biofuels." Climate Change Economics 3 (3): 1-15.

Kislev, Y., and W. Peterson. 1982. "Prices, Technology, and Farm Size.” Journal of Political Economy 90 (3): 578-595.

Kline, K. L., S. Msangi, V. H. Dale et al. 2017. "Reconciling Food Security and Bioenergy: Priorities for Action." GCB Bioenergy 9 (3): 557-576.

Klümper, W., and M. Qaim. 2014. "A Meta-Analysis of the Impacts of Genetically Modified Crops." PloS ONE 9 (11): p.e 111629.

Lichtenberg, E. 2002. "Agriculture and the Environment." In Handbook of Agricultural Economics, vol. 2, edited by B. Gardner and G. Rausser, 1249-1313. Amsterdam: Elsevier Science.

Lichtenberg, E., and R. Zimmerman. 1999. "Information and Farmers' Attitudes about Pesticides, Water Quality, and Related Environmental Effects." Agriculture, Ecosystems and Environment 73 (3): 227-236.

Lipper, L., N. McCarthy, D. Zilberman, S. Asfaw, and G. Branca. 2018. Climate Smart Agriculture: Building Resilience to Climate Change. Rome: FAO; Dordrecht, Netherlands: Springer.

Mullainathan, S., and J. Spiess. 2017. "Machine Learning: An Applied Econometric Approach.” Journal of Economic Perspectives 31 (2): 87-106.

Olmstead, A. L., and P. W. Rhode. 2011. "Responding to Climatic Challenges: Lessons from US Agricultural Development." In The Economics of Climate Change: Adaptations Past and Present, edited by G. Libecap and R. Steckel, 169-194. Chicago: University of Chicago Press.

Pardey, P. G., J. M. Alston, C. Chan-Kang et al. 2018. “The Shifting Structure of Agricultural R\&D: Worldwide Investment Patterns and Payoffs." In From Agriscience to Agribusiness, edited by N. Kalaitzandonakes, E.G.Carayannis, E. Grigoroudis, and S. Rozakis, 13-39. Cham, Switzerland: Springer.

Pardey, P. G., J. M. Alston, and R. Piggott, eds. 2006. Agricultural R\&D in the Developing World. Washington, DC: IFPRI.

Pray, C. E. 2001. "Public-Private Sector Linkages in Research and Development: Biotechnology and the Seed Industry in Brazil, China and India." American Journal of Agricultural Economics 83 (3): 742-747.

Pray, C. E., and K. O. Fuglie. 2015. “Agricultural Research by the Private Sector." Annual Review of Resource Economics 7 (1): 399-424. 
Rasmussen, W. D. 1968. "Advances in American Agriculture: The Mechanical Tomato Harvester as a Case Study." Technology and Culture 9 (4): 531-543.

Rausser, G. C., J. Swinnen, and P. Zusman. 2011. Political Power and Economic Policy: Theory, Analysis, and Empirical Applications. Cambridge: Cambridge University Press.

Reardon, T., and D. Zilberman. 2018. "Climate Smart Food Supply Chains in Developing Countries in an Era of Rapid Dual Change in Agrifood Systems and the Climate." In Climate Smart Agriculture, edited by L. Lipper, N. McCarthy, D. Zilberman, S. Asfaw, and G. Branca, 335-351. Cham, Switzerland: Springer.

Ritchie, H., and M. Roser. 2017 (revised 2019). "Yields and Land Use in Agriculture." Our World In Data. Accessed 2019. https://ourworldindata.org/yields-and-land-use-in-agriculture.

Rosenberg, Nathan. 1990. “Why Do Firms Do Basic Research (with Their Own Money)?” Research Policy 19 (2): 165-174.

Sanchez, P. A. 2010. “Tripling Crop Yields in Tropical Africa." Nature Geoscience 3 (5): 299-300.

Schultz, T. W. 1964. Transforming Traditional Agriculture. New Haven, CT: Yale University Press.

Spielman, D. J., and X. Ma. 2016. "Private Sector Incentives and the Diffusion of Agricultural Technology: Evidence from Developing Countries.” Journal of Development Studies 52 (5): 696-671.

Thaler, R. H. 2015. Misbehaving: The Making of Behavioral Economics. New York: W. W. Norton \& Company.

Thirtle, C., L. Lin, and J. Piesse. 2003. "The Impact of Research-Led Agricultural Productivity Growth on Poverty Reduction in Africa, Asia and Latin America." World Development 31 (12): 1959-1975.

Wesseler, J., R. D. Smart, J. Thomson, and D. Zilberman. 2017. “Foregone Benefits of Important Food Crop Improvements in Sub-Saharan Africa." PloS ONE 12 (7): p.e0181353.

Wesseler, J., and J. von Braun. 2017. "Measuring the Bioeconomy: Economics and Policies." Annual Review of Resource Economics 9 (2017): 275-298.

Wesseler, J., and D. Zilberman. 2014. “The Economic Power of the Golden Rice Opposition.” Environment and Development Economics 19 (6): 724-742.

Wolf, S. 1995. "Cropping Systems and Conservation Policy: The Roles of Agrichemical Dealers and Independent Crop Consultants.” Journal of Soil and Water Conservation 50 (3): 263-270.

Wu, F. 2006. "Mycotoxin Reduction in Bt Corn: Potential Economic, Health, and Regulatory Impacts." Transgenic Research 15 (3): 277-289.

Zilberman, D., G. Hochman, D. Rajagopal, S. Sexton, and G. Timilsina. 2012. “The Impact of Biofuels on Commodity Food Prices: Assessment of Findings." American Journal of Agricultural Economics 95 (2): 275-281. 
Zilberman, D., E. Kim, S. Kirschner, S. Kaplan, and J. Reeves. 2013. “Technology and the Future Bioeconomy." Agricultural Economics 44 (s1): 95-102.

Zilberman, D., L. Lu, and T. Reardon. 2019. "Innovation-Induced Food Supply Chain Design." Food Policy 83: 289-297.

Zilberman, D., J. Zhao, and A. Heiman. 2012. "Adoption versus Adaptation, with Emphasis on Climate Change." Annual Review of Resource Economics 4 (1): 27-53. 